\title{
Property in the Province of Kardhiqi Idioms (Gjirokastra)
}

\author{
Valbona Kalemi \\ Candidate for Doctor's Degree, Tirana; Email: valbonakalemi@yahoo.com
}

\section{Doi:10.5901/ajis.2016.v5n1p227}

\begin{abstract}
Albanian word is one of the creation of the immortal people who, having overcome centuries, have entered our time powerfully because the owner of the largest nation has put his love... The Albanian word expresses the entire life of centuries of our ancient and warrior people, his vast culture well preserved, a glorious history full of battles. (J. Thomas, Tirana 2001: p. 238). Every spiritual world of the people finds its own expression. Idioms are proof of a self-understanding and social, and our ethnolinguistic development. Most of the Albanian phraseology is seen as mostly popular, historical creation which is an indicator of psychology and mentality of our people. The wording of the user decorates discourse of a language, whether in the simple, conversational or artistic. Albanian compared with other languages, is very rich in idioms assessable units. (Memisha.V., Tirana, 2011: p. 81). Phraseologies through ideas get information about people, life, customs, history and culture of and moral behavior.
\end{abstract}

Keywords: phraseological units, speaking, lexicon, synonymous relationship, motivation units, structural modeling.

\section{Aim of Study}

The aim of this study is to reflect the property of popular phraseology, and local nuances of the province of Kardhiqi (Gjirokastra). Linguistic property surprises, they not only give the feeling and emotions, but also characterize the province of ethnographic, sociolinguistic, historical, and environmental data legislated provincial and mentality in the past centuries.

Idioms unit are known values, they bring enrichment and broadening of the means of expression, but also a higher value on content in thrilling hue, it brings many nuances of meanings of uses, the judgment of the people for the things and people. (Thomas. J., Tirana 2006, p. 238). These expressions not only reflect customary norms, traditions, numerous contrasts that characterize the family and social life of these people, but also it is closely acquainted with psychological and spiritual history of residents in this area.

Every lexical unit, semantic idioms, created in a dialectical plot is indivisible unit of the whole, from the Albanian language, as people of the district. Dialect is an inseparable part of the whole Albanian land (J.Thomai 2001: p. 239). Richer grades of words with the popular discourse are those associated with features of work, life, nature and sociocultural development of speakers, such as agriculture,livestock, crafts, tools, processing of products, customs and rituals etc. with those words idioms are constructed on multiple units. (J. Thomai, 2001: p. 240)

With great values of local idioms, with the depth of the sharpness of their beauty, special dialects create a figurative plan, on which are built the popular simple conversations, but rich and beautiful. (J. Thomai 2001: p. 242)

\section{Methodology}

The material is collected in the field and the treatment is done according to the rules of science of Albanian language. We will reflect the lexicon and grammatical value that these unit idioms are worth of the nominal, adjectival, adverbial, motivation units, the unmotivation modeling structural units of idioms and popular proverbs, structure one part of speech, two parts of speech, three parts of speech and special structural sentences we gathered in speaking language. Often almost popular phraseology of this area looks a bit like artistic style. These phraseology collected in the field come from representatives of the older generation that implies linguistic natural conservation property. A part of this phraseology has been reflected (Kalemi. V., 2014). From the collection you feel archaic forms, and forms of words phonetically different from other dialects by, noting at the same time the phonetic changes, morphological, syntactic language fastidious in this area. 


\section{Introduction}

Kardhiqi region is situated in southern Albania in the north-west of Gjirokastra town. Cultural and linguistic values are underlined a little while ago with our presentations. Province of Kardhiqi is a center of ancient Illyrian civilization. This is an inexhaustible wealth that is part of the Albanian culture. It is known that idioms are rich with popular words and phrases that are important. This creativity found in the dialect in most of the cases it has tended to generalize, to become the property of the formal language, to enrich it with new semantic and stylistic lexicon value. Tracking, collection and study are not only a scientific task, but also a patriotic duty.

Idiom unit is a unit of linguistic autonomous meaning, consisting of two or more words, with sustainable building, formed historically for a long time, that has the value of a single word, reproduced in speaking as ready and functions as an inseparable unit in the language. (Thoma J., Tirana 1999: p. 210-211).

It is known that the formation of phraseologies is done historically and in a long time, most of them have nationwide approach.

The wording of the living language, there are more figurative and emotional burden precisely distinguishing these from library, cultural phraseology, which is mostly taken from other languages. Figurative language expressions often live description of significant facts related to emotional associations, dealing with the history of the people and the country, life and culture of the people (Lloshi. J.., Tirana 1999 : p. 127). Today phraseology researchers see it as a field of linguistic studies that expresses the connection between language and culture to a higher level. (A. P. Cowe, New York 1998, p. 54-56; Jean-Pierre Colson, Berlin 2007: p. 193).

This is because the units associated with the tradition idioms habits, which are characteristic of culture, time for certain developments.

The phraseology is created from the translation of free symbolic notions. Some researchers consider idiom unit as a linguistic unit that expresses the mentality of a nation and its culture. Various studies on phraseology, the approach that might do and differences between units of different people see them also have their own distinctive characteristics. Psycho-emotional events affect the human condition. Language reflects the culture, traditions, history, mentality, scientific and technological achievements of a society. (M. Bamberg, 1997: p. 209-226).

Albanian phraseology has determined theoretically and practically its units basic lexicon-semantic. (Xh. Lloshi, 1970; pp. 31-50).

Phraseology, the multiplicity and diversity of popular sayings that bring local color to this area, Kardhiqi southern province. Through the language used means of expression reflected the life of a resident of this province. They express feelings, emotions, and also characterize the province of ethnographic, sociolinguistic, historical, drawing data about this environment, and the mentality of the residents. Their surprising multiplicity reflected noble spirit of the Albanian people.

Corps collected in the field from being listed some syntagmatic uses.

He has ruptured the hulls of the forehead, the dropped tail that adze, made on soles, thick and wide, we trembled legs, not kill mind all, he set fire to the house, I came around and around the house, there is a burden children, stripped him pinch mind has made crazy, and hearkened not mind at all, do not let row for one, do not leisurely conversation, not harassed his son, as he found the side, do not mind turns as head on to get evil just doing sacrifice, that I neither tribes nor seed, is our front door, he left the pen, they more evil, learn to five hundred good, like night and day, we to live of I have as far as it is brought to the top of nose, put Huns, as has practiced peak blood, I had practiced more, he fell toiled and sweated as leave anything undone, to cry plight, I'm anthrax. On toast in cartons, as black life.

These arise from the phraseology of representatives of the older generation, that means the storage phase. Generally the phraseology is used by the female sex which is part of the male sex, mainly in villages traditionally the division of labor is both as a social division of speech and ways of expression. Prof. Gj. Shkurtaj that "The first division is greater in quantity of speech, women being the majority of cases to perform work that can be accompanied with talks of deliberations that does not ban their performance, talk more, they are more open minded to talking and with the time has become their distinguishing feature". (Shkurtaj. Gj., Tirana, 1999: p. 234).

In speaking province even more synonymous units note: not that sheds more inwards, did not hang bag, you can't make out the important from the least important, there stands the largest of the youngest, became legs of a goat, not busy work hand, does not budge.

Antonymous relations: not disrupting anything, it did not stay a minute cosily, not working with hand touch, I don't see a white day, living in the lap of luxury.

The phraseology collected is analyzed by -grammatical lexicon value, we have four groups: 
1. Idioms with nominal value units are those units functioning as names: the scorn of the world, the god lamb, lamb stream, man woolly pig in a poke.

2. Idioms units worth as adjectives: kills with shoulder drop of lead, the great door, the girls remaind home, I know my fists, to drink in the cup, as done magic, I died and without insert (it is) for you lay out eyes.

3. Unit verbal idioms, does not know the word, and went through the hands, do not step on, burned the house, stopped the door, gave me water blood, keep mouth, makes a deaf ear.

4. Unit adverbial value idioms: blood cut, with frozen blood, know the with molar is closed under, and has ruptured the hulls, for the mind of the head., hand and feet.

In this idiom have also motivation unit, here we have two groups of units idioms:

Modeling the structure of local idioms and popular sayings. Structural model of these units have the structure:

1. Structure part of speech are not numerous, but mainly have cases such as hibernate.

a) The first group: We have units that have come from the conversion of free symbolic phrases: as my door under the door, the bread went behind his back, puts the house on fire.

b) The second group: There are units built on a part with mainly figurative verb and direct sense, makes me hot, I have leisure has become Dill, he broke my nose.

Units without motivation

Units consisting of unmotivational parts: have limbs as I fell toiled and sweated, has temper hum,

Units coming from historical events and anecdotes or happenings as: like turtles to smith, like lambs to the slaughter, like the goat in milking place.

Units that are not free from compound words: do not kill mind, takes on the evil being, assemble mind.

Modeling the structure of local idioms and proverbs. Structural model of these units have this structure:

One part of speech structure are not a lot, but generally we have these cases: relax, sunbathe, lie in bed.

2. Two part of speech sctructure

Noun + noun: a nap, washed and unwashed, head over heels, woe upon woe, with a child row, with a load of children.

noun + adjective: woolen man with frozen blood, torn mouth

Adjective + noun: crazy man

Adjective + noun: dead without inser

Verb + adverb: crawled and crawled

Noun + verb: the rumored talk, laugh yarn

Verb + noun: remove from the mind of himself in the abdomen and died, no friend, I toiled and sweated fell, broke his neck, no heart, was cut hopes

Verb + adverb: falls short, I told her piece.

Adjective + noun + verb: not a day we saw white

Verb + noun + noun: is made buttermilk mind, I know the molar tooth, became eye cup, mounted in place of the head

Verb + noun: eat ourselves with teeth

Sentence structure: has all beneath the skin, I know you know the words made

From what we have noticed a few large number of these structures used I note in the surrounding dialects.

\section{Conclusion}

In conclusion we can say that there are many in this idiom modeling the structure of phraseological units and their uses, which have been inherited from generation to generation, they have become part of our everyday discourse. This phraseological models are in great numbers in everyday speaking that are considered in new forms nearby area, but every speaking model has its own form with different phonetic and meaning, and different shades of usage.

In this phraseology is presented all history and native culture. The science of Albanian Linguistics is interested in collecting of words and folk phrases in order to come out the priceless treasure of popular inheritance. This must present in the Albanian Language as part of the formal language. The importance of phraseology is always in the spotlight of linguists for the prosperity that it brings. 


\section{References}

Shkurtaj. K., (1999), Sociolinguistics, Tirana.

Thomas. J., (1999), Lexicology of Albanian, Tirana.

M. Bamberg, (1997) Emotional talk (s): the role of perspective in the construction of emotions, The Language of Emotions II, Amsterdam, Philadelphia.

Pen. V., (2014), The wording on the animal world in the valley of Kardhiqit in linguistic research III, Science week, QSA.

(Lloshi. Xh., (1999), Stylistics and Pragmatics, General Stylistics, Tirana.

Lloshi. Xh., (1970), On the Study of Stylistic Albanian Features, SF., Nr. 1.

J. Thomas (2001), The Regional dialectal vocabulary in today's Albanian, Albanian Academy, of Tirana.

Jean-Pierre Colson (2007), Phraseological linguistic Crros-, studies in phraseology, an Interdisciplinary perspective, Berlin.

Memisha. V., (2011), Studies for Albanian word, Tirana.

Kalemi. V.,(2014), Phraseology in animal world in Kardhiqi valley, Linguistic researches III, Science week, Albanian Research Centre. Thomas, J, (2006), Lexicology of Albanian, Tirana. 